\title{
Effects of the ATP, ADP and inorganic phosphate on the transport rate of the $\mathrm{Na}^{+}, \mathrm{K}^{+}$-pump
}

\author{
H.-J. Apell, M.T. Nelson *, M.M. Marcus and P. Läuger \\ Department of Biology, University of Konstanz, D-7750 Konstanz (F.R.G.)
}

(Received November 19th, 1985) Key words: $\left(\mathrm{Na}^{+}+\mathrm{K}^{+}\right)$-ATPase; Membrane reconstitution; Product inhibition;
Kinetics; Fluorescence; (Rabbit kidney)

$\left(\mathrm{Na}^{+}+\mathrm{K}^{+}\right)$-ATPase from kidney outer medulla was incorporated into artificial dioleoylphosphatidylcholine vesicles. In the reconstituted system the pump can be activated by adding ATP to the external medium. ATP-driven potassium extrusion by the $\mathrm{Na}^{+}, \mathrm{K}^{+}$-pump was studied using a voltage-sensitive dye in the presence of valinomycin. ADP strongly reduced the turnover rate of the pump with a concentration for half-maximal inhibition of $c_{\mathrm{D}, 1 / 2}=0.1 \mathrm{mM} . c_{\mathrm{D}, 1 / 2}$ was found to be virtually independent of ATP concentration, indicating that the inhibition is non-competitive with respect to ATP. The non-competitive inhibition by ADP can be explained on the basis of the Post-Albers reaction cycle of the $\mathrm{Na}^{+}, \mathrm{K}^{+}$-pump, assuming that the main action of ADP is the reversal of the phosphorylation step. A similar 'product inhibition' was observed with inorganic phosphate, but at much higher concentrations $\left(c_{\mathrm{P}, 1 / 2}=14 \mathrm{mM}\right)$.

\section{Introduction}

The $\left(\mathrm{Na}^{+}+\mathrm{K}^{+}\right)$-ATPase translocates sodium and potassium ions across the cell membrane, utilizing ATP as an energy source [1-6]. Since ADP and inorganic phosphate $\left(P_{i}\right)$ are the products of the enzymatic reaction, the pumping rate should depend, at a given ATP concentration, on the cytoplasmic concentrations of ADP and $P_{i}$. In the course of the pumping cycle, an ATP molecule binds to the protein, and subsequently the protein is phosphorylated by the bound ATP. In the presence of ADP in the medium, the phosphorylation step may be reversed, i.e., ADP may combine with the phosphorylated protein and form ATP. In this way ADP (and, by a similar argument, $P_{i}$ ) should decrease the turnover rate of the pump. In addition to this direct effect on the pumping cycle,

\footnotetext{
* Permanent address: Department of Pharmacology, University of Miami, School of Medicine, Miami, FL 33101, U.S.A.
}

ADP may compete with ATP for ATP-binding sites on the enzyme.

Experimental studies of the effects of ADP and $P_{i}$ in intact cells, which require the manipulation of the cytoplasmic concentrations of these compounds, are technically difficult [7-10]. A number of ion-flux experiments have been carried out with resealed erythrocyte ghosts utilizing regenerating systems for ADP and ATP [11-13]. Furthermore, the influence of ADP and $\mathrm{P}_{\mathrm{i}}$ on ATP hydrolysis rate has been investigated with isolated enzyme or microscopic preparations containing $\left(\mathrm{Na}^{+}+\mathrm{K}^{+}\right)$ATPase [14-19].

Artificial lipid vesicles with incorporated $\left(\mathrm{Na}^{+}\right.$ $+\mathrm{K}^{+}$)-ATPase offer the possibility of studying ion transport rates under easily controllable conditions [20-28]. Reconstituted vesicles prepared by cholate dialysis have diameters of about $90 \mathrm{~nm}$ and contain up to 10-20 pump molecules in random orientation [29-33]. Directionality of transport is achieved by adding ATP to the external 
medium, thereby activating only pump molecules with outward facing ATP binding sites. Since the volume of the external medium is very large, concentration changes of ATP, ADP and $P_{i}$ during the experiment are negligible under most conditions.

In the following, we describe experiments with reconstituted $\left(\mathrm{Na}^{+}+\mathrm{K}^{+}\right)$-ATPase vesicles using an optical method for the detection of ATP-driven potassium fluxes $[32,33]$. The membrane voltage of the vesicles is measured by monitoring the fluorescence of a voltage-sensitive indocyanine dye. By addition of valinomycin, the vesicle membrane is made selectively permeable to $\mathrm{K}^{+}$ions so that the membrane voltage approaches the Nernst potential for $\mathrm{K}^{+}$. With constant external $\mathrm{K}^{+}$concentration, the time-course of internal $\mathrm{K}^{+}$concentration can be continuously measured as a change of fluorescence signal after activation of the pump. The optical method has a higher time resolution than tracer-flux experiments and allows an accurate determination of initial flux rates.

\section{Materials and Methods}

Dioleoylphosphatidylcholine was obtained from Avanti Polar Lipids, Birmingham, AL; ATP was from Boehringer-Mannheim (Sonderqualität), ADP and AMP from Sigma and TNP-ADP from Molecular Probes, Junction City, OR, U.S.A. The ADP content of the ATP was checked by HPLC and was found to be less than $0.2 \% .1,3,3,1^{\prime}, 3^{\prime}, 3^{\prime}$ hexamethylindodicarbocyanine (NK 529) was purchased from Nippon Kankoh Shikiso Kenkyusho, Okayama, Japan. All other reagents were obtained from Merck (analytical grade). Dialysis tubing was purchased from Serva, Heidelberg.

$\left(\mathrm{Na}^{+}+\mathrm{K}^{+}\right)$-ATPase was prepared from the outer medulla of rabbit kidneys using procedure $\mathrm{C}$ of Jørgensen [35], as described previously [32,36]. The specific activity was in the range of 1850-2100 $\mu \mathrm{mol} \mathrm{P}_{\mathrm{i}}$ per $\mathrm{h}$ per $\mathrm{mg}$ protein at $37^{\circ} \mathrm{C}$. The enzyme was solubilized in a solution of $23 \mathrm{mM}$ sodium cholate in 'buffer H' (30 mM imidazole/ 1 $\mathrm{mM}$ L-cysteine/ $1 \mathrm{mM}$ EDTA/and $5 \mathrm{mM} \mathrm{MgSO}_{4}$; the $\mathrm{pH}$ was adjusted to 7.2 with $\mathrm{H}_{2} \mathrm{SO}_{4}$ ). The enzyme solubilizate was mixed with dioleoylphosphatidylcholine solubilized in cholate buffer. The mixture (10 $\mathrm{mg}$ lipid and about $0.6 \mathrm{mg}$ protein per $\mathrm{ml}$ ) was dialyzed against buffer $\mathrm{H}$ containing $70 \mathrm{mM} \mathrm{K}_{2} \mathrm{SO}_{4}$ and $5 \mathrm{mM} \mathrm{Na}{ }_{2} \mathrm{SO}_{4}$ $[32,36]$. The resulting vesicles had an average diameter of $96 \mathrm{~nm}$ with a half-width of the distribution of $\pm 10 \mathrm{~nm}[32,37]$.

The fluorescence of the indocyanine dye was measured as described previously [32]. The excitation wavelength was set to $620 \mathrm{~nm}$ (slit width 5 $\mathrm{nm}$ ) and the emission wavelength to $680 \mathrm{~nm}$ (slit width $20 \mathrm{~nm}$ ). The thermostatically controlled cell, which was equipped with a magnetic stirrer, was filled with $1 \mathrm{ml}$ buffer $\mathrm{H}$ containing $5 \mathrm{mM} \mathrm{K}_{2} \mathrm{SO}_{4}$, $70 \mathrm{mM} \mathrm{Na} \mathrm{SO}_{4}, 2.3 \mu \mathrm{M}$ of the dye and various amounts of ADP or $\mathrm{P}_{\mathrm{i}} .5 \mu 1$ of the vesicle suspension containing approx. $10 \mathrm{mg}$ lipid/ml was added to the solution in the cell. When the fluorescence signal had reached a steady level, valinomycin was added from a concentrated stock solution in ethanol to give a total concentration 20 $\mathrm{nM}$. After activation of the pump by addition of ATP to the medium, the time-course of the fluorescence signal was recorded.

The analysis of the experimental data requires a calibration of the relative fluorescence change, $\Delta F / F_{0}$, as a function of membrane voltage, $U\left(F_{0}\right.$ is the fluorescence signal prior to the addition of valinomycin). As described previously [32], the calibration was carried out by measuring $\Delta F / F_{0}$ at different ratios of internal and external $\mathrm{K}^{+}$ concentrations in the presence of valinomycin, using the Nernst equation. In the data analysis, the size distribution of the vesicles was accounted for explicitly, as well as the distribution in the number of pump molecules per vesicle [32]. It was assumed that the number of vesicles containing zero, one, two, etc., pump molecules with the ATP binding site facing outward is given by Poisson's statistics. A theoretical curve was fitted to the observed time-course of $\Delta F / F_{0}$ with the turnover rate, $v_{\mathrm{m}}$, and the average number, $n_{\mathrm{P}}$, of pump molecules per vesicle as adjustable parameters [32], assuming that two $\mathrm{K}^{+}$ions move outward and three $\mathrm{Na}^{+}$ions inward per turnover. For a given vesicle preparation, experiments with different concentrations of ATP, ADP and $\mathrm{P}_{\mathrm{i}}$ could always be fitted with a single value of $n_{\mathrm{P}}$ (and variable $v_{\mathrm{m}}$ ), as would be expected. 


\section{Results}

The time-course of the signal after activation of the pump is shown in Fig. $1 . \Delta F / F_{0}$ is the relative change of fluorescence intensity, referred to the fluorescence intensity, $F_{0}$, prior to the addition of valinomycin. At the beginning of the experiment the interior of the $\left(\mathrm{Na}^{+}+\mathrm{K}^{+}\right)$-ATPase vesicles contained $140 \mathrm{mM} \mathrm{K}^{+}$and $10 \mathrm{mM} \mathrm{Na}^{+}$, and the medium $10 \mathrm{mM} \mathrm{K}^{+}$and $140 \mathrm{mM} \mathrm{Na}$. Indocyanine dye, valinomycin and ADP were then added successively. The fluorescence change after addition of valinomycin reflects the establishment of the Nernst potential for $\mathrm{K}^{+}$. When ATP is added to the medium, $\mathrm{K}^{+}$is extruded from the vesicles and the Nernst potential decreases.

In Fig. 2 the time-course of the fluorescence signal is shown for different concentrations of ADP. The transport rate strongly decreases with increasing ADP concentration. The dotted lines have been calculated according to the fitting procedure described in Ref. 31 with fixed values of the average vesicle diameter $(\bar{r}=45 \mathrm{~nm})$, the vari-

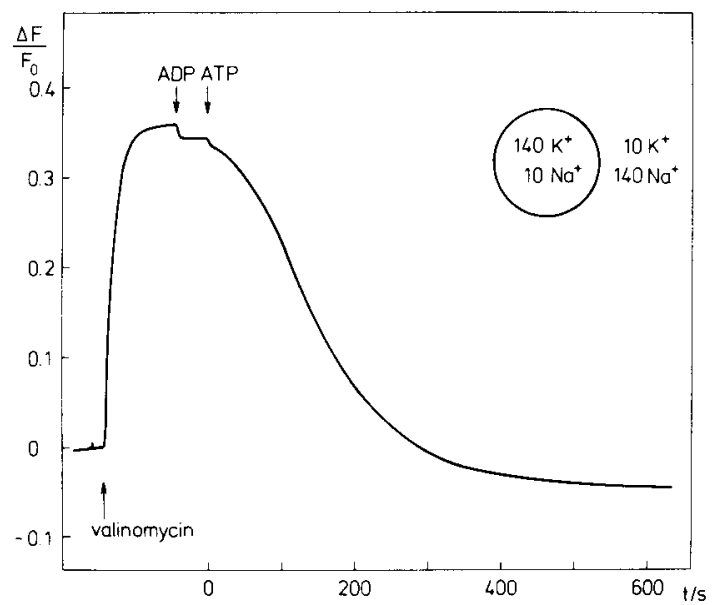

Fig. 1. Change of fluorescence intensity, $\Delta F$, divided by the fluorescence intensity $F_{0}$ prior to the addition of valinomycin. $\left(\mathrm{Na}^{+}+\mathrm{K}^{+}\right)$-ATPase vesicles were formed in buffer $\mathrm{H}$ containing $70 \mathrm{mM} \mathrm{K}{ }_{2} \mathrm{SO}_{4}$ and $5 \mathrm{mM} \mathrm{Na}_{2} \mathrm{SO}_{4} .5 \mu \mathrm{l}$ of the vesicle suspension $(10 \mathrm{mg}$ lipid/ml) were diluted into $1 \mathrm{ml}$ buffer $\mathrm{H}$ containing $5 \mathrm{mM} \mathrm{K}_{2} \mathrm{SO}_{4}, 70 \mathrm{mM} \mathrm{Na} \mathrm{SO}_{4}$ and $2.3 \mu \mathrm{M}$ indocyanine dye. Thereafter, $20 \mathrm{nM}$ valinomycin, $100 \mu \mathrm{M}$ ADP and $2.5 \mathrm{mM}$ ATP were added successively. The fast signal changes after addition of ADP and ATP result from the dilution of the medium. The temperature was $19.6^{\circ} \mathrm{C}$. The concentrations of $\mathrm{Na}^{+}$and $\mathrm{K}^{+}$in the inset are given in mM.

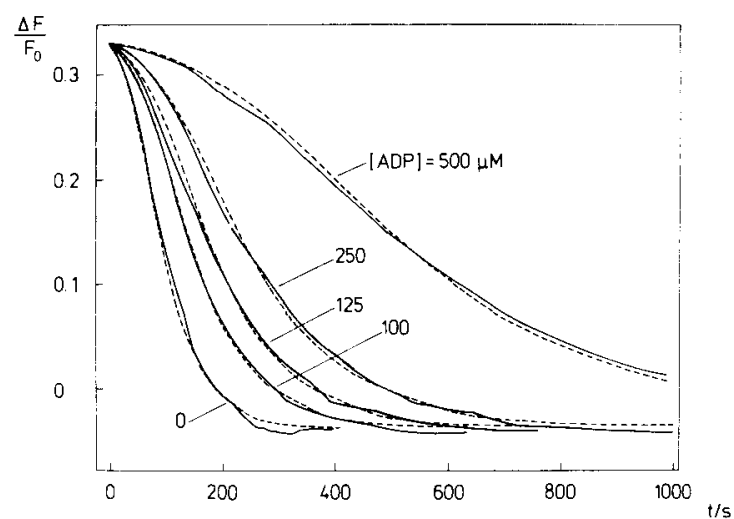

Fig. 2. ATP-driven potassium extrusion at different ADP concentrations. Apart from the ADP concentrations, the experimental conditions were the same as described in the legend of Fig. 1. The experimental curves (full lines) have been corrected for the small dilution effect upon ADP and ATP addition. The theoretical curves (dotted lines) have been calculated according to the fitting procedure described in reference 18 using the following parameter values: $\bar{r}=45 \mathrm{~nm}, \sigma=10 \mathrm{~nm}, n_{\mathrm{P}}=5.2$ ( $\tilde{r}$, average vesicle radius; $\sigma$, variance of $r ; n_{\mathrm{P}}$, average number of pump molecules (ATP-binding site facing outward) per vesicle). The only parameter which varies from curve to curve is the turnover rate, $v_{\mathrm{m}}$, of the pump: $v_{\mathrm{m}}=3.7 \mathrm{~s}^{-1}$ ([ADP] $=$ $500 \mu \mathrm{M}) ; 8.0 \mathrm{~s}^{-1}(250 \mu \mathrm{M}) ; 13.0 \mathrm{~s}^{-1}(125 \mu \mathrm{M}) ; 10.5 \mathrm{~s}^{-1}(100$ $\mu \mathrm{M}) ; 20.0 \mathrm{~s}^{-1}(0 \mathrm{mM}) . v_{\mathrm{m}}$ is defined as the maximum turnover rate in the limit of infinitely large internal $\mathrm{K}^{+}$concentration $c_{\mathbf{K}}^{i}$; at $c_{\mathbf{K}}^{i}=140 \mathrm{mM}, v_{\mathbf{m}}$ is virtually identical with the initial turnover rate.

ance of vesicle radii $(\sigma=10 \mathrm{~nm})$, and of the average number of pump molecules (ADP-binding site facing outward) per vesicle $\left(n_{\mathrm{P}}=6.2\right)$. The only parameter which varies from curve to curve is the turnover rate, $v_{\mathrm{m}} . v_{\mathrm{m}}$ is defined as the maximum turnover rate in the limit of infinitely large internal potassium concentration $c_{\mathrm{K}}^{\mathrm{i}}$. At $c_{\mathrm{K}}^{\mathrm{i}}=140$ $\mathrm{mM}, v_{\mathrm{m}}$ is virtually identical to the initial turnover rate. The fact that all curves for different ADP concentrations can be fitted with the same values of $\bar{r}$ and $n_{\mathrm{P}}$ represents an a posteriori justification of the assumptions implicit in the analysis [32].

The turnover rate, $v_{\mathrm{m}}$, is plotted in Fig. 3 as a function of ADP concentration, $c_{D}$, for three different concentrations of ATP. The experimental values of $v_{\mathrm{m}}$ at all three ATP concentrations (2.5 $\mathrm{mM}, 250 \mu \mathrm{M}$ and $10 \mu \mathrm{M}$ ) can be approximately fitted by the empirical equation:

$v_{\mathrm{m}}=v_{\mathrm{m}}^{0}\left(c_{\mathrm{T}}\right) \frac{K_{\mathrm{i}}}{K_{\mathrm{i}}+c_{\mathrm{D}}}$ 


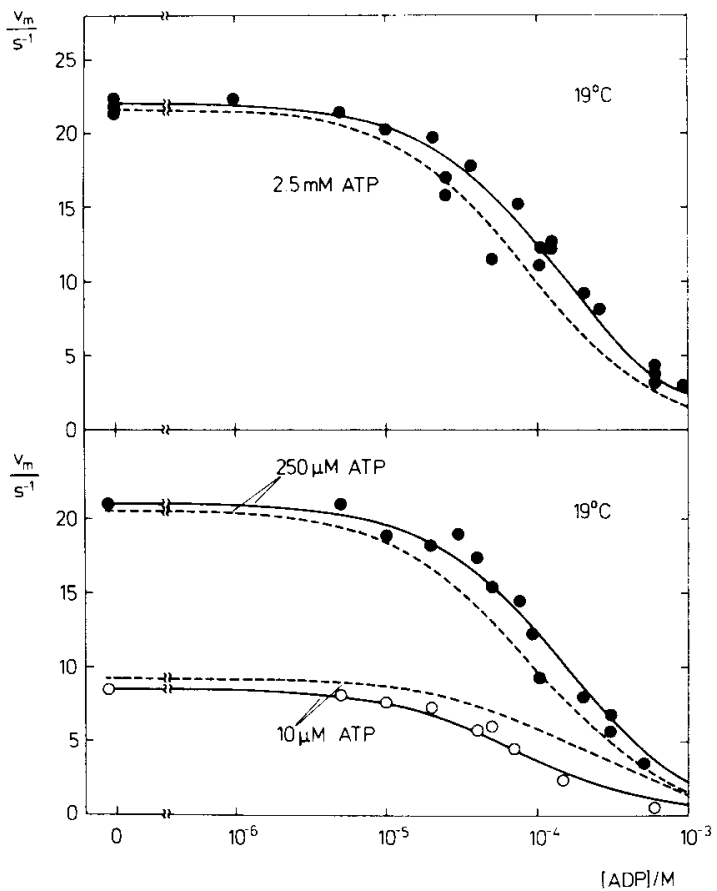

Fig. 3. Turnover rate, $v_{\mathrm{m}}$, as a function of ADP concentration for three different concentrations of ATP; $T=19^{\circ} \mathrm{C}$. Except for the concentrations of ADP and ATP the experimental conditions were the same as indicated in the legend of Fig. 1. $v_{\mathrm{m}}$ was evaluated according to the fitting procedure described in Ref. 31. The solid lines were calculated according to Eqn. 1 with $K_{\mathrm{i}}=130 \mu \mathrm{M}(2.5 \mathrm{mM}$ ATP $), K_{\mathrm{i}}=140 \mu \mathrm{M}(250 \mu \mathrm{M}$ ATP) and $K_{\mathrm{i}}=80 \mu \mathrm{M}(10 \mu \mathrm{M} \mathrm{ATP})$. The dashed lines were obtained by numerical simulation of the reaction cycle using the parameter values listed in Table I; the calculated rates were multiplied by a temperature correction factor of 0.58 .

with $K_{\mathrm{i}}=0.1 \mathrm{mM} \cdot v_{\mathrm{m}}^{0}\left(c_{\mathrm{T}}\right)$ is the turnover rate in the absence of ADP at a given value of ATP concentration, $c_{\mathrm{T}}$, and $K_{\mathrm{i}}$ is the ADP concentration at which the inhibition is half-maximal. The constant $K_{\mathrm{i}}$ is found to be virtually independent of ATP concentration in a 250 -fold concentration range. This indicates that the inhibition by ADP is non-competitive with respect to ATP. A plot of $1 / v_{\mathrm{m}}$ versus $1 / c_{\mathrm{T}}$ for different values of $c_{\mathrm{D}}$ (not shown) yields a series of straight lines intersecting in a common point at $1 / v \approx 0,1 / c_{\mathrm{T}}=-55$ $\mathrm{mM}^{-1}$. As discussed later, this behaviour can be explained by the assumption that binding of ATP and phosphorylation of the protein take place in two separate steps of the reaction cycle. In order to test the specificity of the ADP effect, the influence of two other nucleotides has been investi-

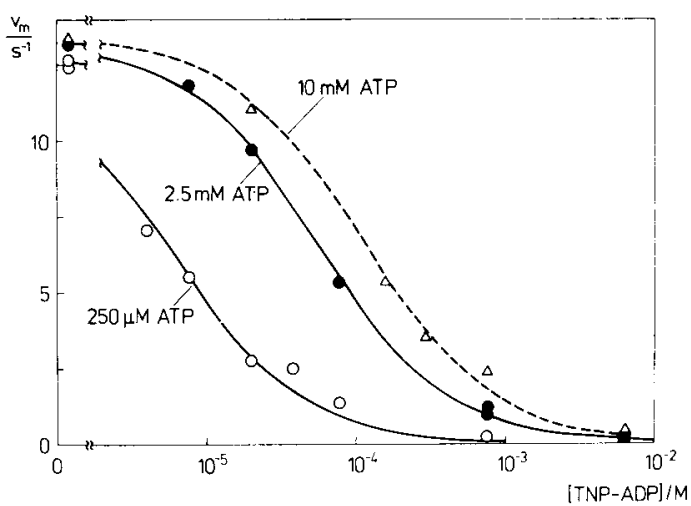

Fig. 4. Turnover rate as a function of TNP-ADP concentration; $T=16.0^{\circ} \mathrm{C}$. Except for the nucleotide concentrations, the experimental conditions were the same as indicated in the legend of Fig. 1. The lines have been drawn by eye.

gated. Adenosine monophosphate (AMP) did not affect the pumping rate up to concentrations of $2.5 \mathrm{mM}$ in the presence of $2.5 \mathrm{mM}$ ATP. $2^{\prime}, 3-O-$ (2,4,6-trinitrocyclohexadienylidene)adenosine diphosphate (TNP-ADP), a well-known competitor of ATP at the ATP-binding site [34,41], strongly inhibited the pump (Fig. 4), but, in contrast to the findings with $\mathrm{ADP}$, the concentration for halfmaximal inhibition was dependent on ATP concentration. A plot of $1 / v_{\mathrm{m}}$ as a function of 1/[ATP] at different TNP-ADP concentrations (not shown) indicates that the inhibition by TNPADP is competitive with respect to ATP, with an

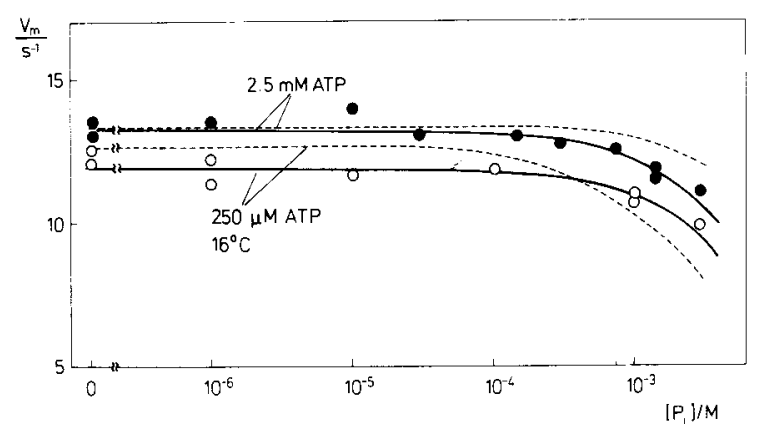

Fig. 5. Turnover rate $v_{\mathrm{m}}$ as a function of phosphate concentration $c_{\mathrm{P}}$ at $16.0 \pm 0.2^{\circ} \mathrm{C}$ for two different $\mathrm{ATP}$ concentrations; $[\mathrm{ADP}]=0$. The other conditions were the same as indicated in the legend of Fig. 1. The solid lines have been drawn according to the equation $v_{\mathrm{m}}=v_{\mathrm{m}}^{0} K_{\mathrm{i}} /\left(K_{\mathrm{i}}-c_{\mathrm{P}}\right)$ with $K_{\mathrm{i}} \approx 14 \mathrm{mM}(2.5$ $\mathrm{mM}$ and $250 \mu \mathrm{M}$ ATP). The dashed lines were calculated by numerical simulation of the reaction cycle using the parameter values listed in Table I; the calculated rates were multiplied by a temperature correction factor of 0.36 . 


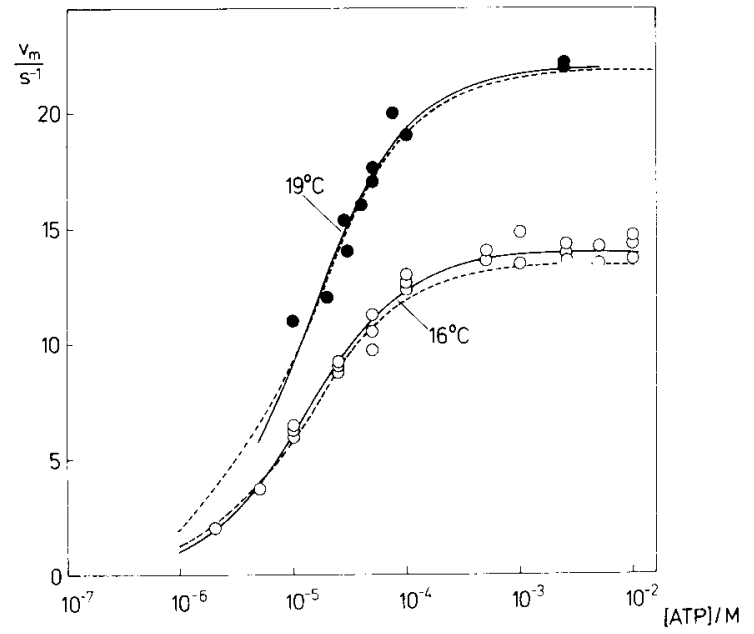

Fig. 6. Turnover rate, $v_{\mathrm{m}}$, as a function of ATP concentration $c_{T}$ at (nominally) zero concentrations of ADP and $P_{j}$. At ATP concentrations above $2.5 \mathrm{mM}$ an equivalent amount of $\mathrm{Mg}^{2+}$ was added to buffer $H$ in order to keep the concentrations of free $\mathrm{Mg}^{2+}$ at about $2.5 \mathrm{mM}$. See Refs. 59 and 60 for a discussion of $\mathrm{Mg}^{2+}$ effects. The other conditions were the same as indicated in the legend of Fig. 1. The solid lines have been drawn according to the equation $v_{\mathrm{m}}=v_{\mathrm{m}}^{*} c_{\mathrm{T}} /\left(c_{\mathrm{T}}+K_{\mathrm{m}}\right)$ with $K_{\mathrm{m}}=13 \mu \mathrm{M}\left(16.0^{\circ} \mathrm{C}\right)$ and $14 \mu \mathrm{M}\left(19.4^{\circ} \mathrm{C}\right)$. The dashed line $\left(16.0^{\circ} \mathrm{C}\right)$ was calculated by numerical simulation of the reaction cycle using the parameter multiplied by temperature correction factors of $0.36\left(16.0^{\circ} \mathrm{C}\right)$ and $0.58\left(19.4^{\circ} \mathrm{C}\right)$.

inhibition constant of about $0.4 \mu \mathrm{M}$. Thus, ADP and TNP-ADP seem to inhibit pumping activity by entirely different mechanisms. The conclusion that TNP-ADP competes with ATP for the ATPbinding site is consistent with the results obtained by Moczydlowski and Fortes [41] with another non-hydrolyzable TNP nucleotide, TNP-ATP.

Whereas ADP has a strong effect on the pumping rate, the other product of the enzymatic reaction, inorganic phosphate $\left(P_{i}\right)$, inhibits only weakly up to concentrations in the millimolar range (Fig. 5). The observed effect should be considered as an upper limit of the inhibitory action of $\mathrm{P}_{\mathrm{i}}$, since addition of $3 \mathrm{mM} \mathrm{P}_{\mathrm{i}}$ to the medium is likely to reduce the activity coefficient of $\mathrm{Mg}^{2+}$.

The dependence of pumping rate on ATP concentration $c_{\mathrm{T}}$ at (nominally) zero concentrations of ADP and $P_{i}$ is given in Fig. 6 for two different temperatures $\left(16.0\right.$ and $\left.19.4^{\circ} \mathrm{C}\right)$. In the experimental range of $c_{\mathrm{T}}(10 \mu \mathrm{M}$ to $10 \mathrm{mM})$ the observed turnover rate $v_{\mathrm{m}}$ can be approximately fitted with the equation

$v_{\mathrm{m}}=v_{\mathrm{m}}^{*} \cdot \frac{c_{\mathrm{T}}}{c_{\mathrm{T}}+K_{\mathrm{m}}}$

The curves in Fig. 6, which have been drawn using $K_{\mathrm{m}}$ values of $13 \mu \mathrm{M}\left(16.0^{\circ} \mathrm{C}\right)$ and $14 \mu \mathrm{M}\left(19.4^{\circ} \mathrm{C}\right)$, are consistent with the predictions of the Post-Albers reaction scheme, as discussed later. Since the fluorescence signal has to be monitored during a finite time interval ( $\Delta t \geq 100 \mathrm{~s}$ ) for reliable data analysis, the experiments are restricted to ATP concentrations which remain sufficiently constant during $t$. In practice, this means that $c_{T}$ has to be larger than $10 \mu \mathrm{M}$. (An upper limit for the ATP consumption during the experiment may be estimated in the following way. At the given vesicle concentration in the fluorescence cell, the ratio of internal to external aqueous volume is about 5 . $10^{-5}$ as determined by the ${ }^{137} \mathrm{Cs}^{+}$method [32]. With an initial $\mathrm{K}^{+}$concentration inside the vesicles of $140 \mathrm{mM}$, the overall internal $\mathrm{K}^{+}$concentration is $7 \mu \mathrm{M}$. Since (in the presence of valinomycin) three $\mathrm{K}^{+}$ions leave the vesicle per hydrolyzed ATP, the change of ATP concentration after complete extrusion of $\mathrm{K}^{+}$is about $2 \mu \mathrm{M}$.)

\section{Discussion}

In the experiments described above a strong, non-competitive inhibitory effect of ADP on the $\mathrm{Na}^{+}, \mathrm{K}^{+}$-pump has been observed with half-maximal inhibition at $c_{\mathrm{D}, 1 / 2} \approx 0.1 \mathrm{mM}$ ADP. The value of $c_{\mathrm{D}, 1 / 2}$ is in the range of physiological ADP concentrations [50]; it is thus feasible that inhibition by ADP represents a kind of negative-feedback mechanism by which the activity of the $\mathrm{Na}^{+}, \mathrm{K}^{+}$-pump is reduced when the cytoplasmic ADP concentration increases above the normal level.

In the following, we discuss the possible mechanism of the ADP effect on the basis of the PostAlbers cycle of the $\left(\mathrm{Na}^{+}+\mathrm{K}^{+}\right)$-ATPase $[3,38,39]$. It is obvious from the reaction scheme (Fig. 7) that ADP may interfere with the pumping cycle in several different ways. It may compete with ATP in (low-affinity) binding to $\mathrm{E}_{2}\left(\mathrm{~K}_{2}\right)$, i.e., it may inhibit the reaction $\mathrm{E}_{2}\left(\mathrm{~K}_{2}\right) \rightarrow \mathrm{ATP} \cdot \mathrm{E}_{2}\left(\mathrm{~K}_{2}\right)$; it may also compete with ATP for any of the states $\mathrm{K}_{2} \cdot \mathrm{E}_{1}, \mathrm{E}_{1}$, and $\mathrm{Na}_{3} \cdot \mathrm{E}_{1}$ which bind nucleotides 


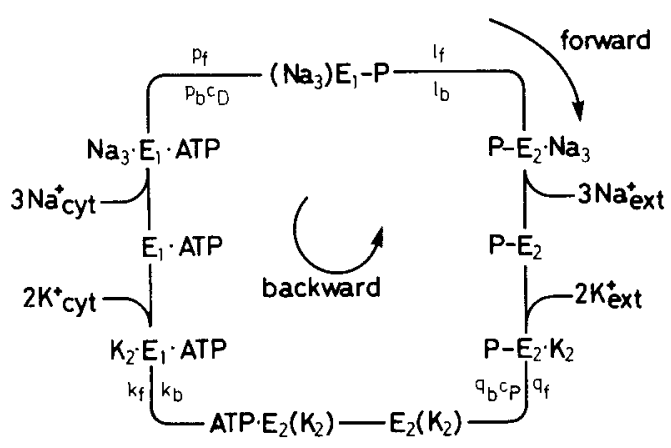

Fig. 7. Post-Albers reaction cycle of the $\mathrm{Na}^{+}, \mathrm{K}^{+}$-pump. $\mathrm{E}_{1}$ and $E_{2}$ are conformations of the enzyme with ion binding sites facing the cytoplasm and the extracellular medium, respectively. A non-covalent bond is indicated by a dot and a covalent hond by a dash. $\left(\mathrm{Na}_{3}\right)$ and $\left(\mathrm{K}_{2}\right)$ refer to 'occluded' states in which bound alkali ions are unable to exchange with the aqueous phase. $p_{\mathrm{f}}, l_{\mathrm{f}}, q_{\mathrm{f}}, k_{\mathrm{f}}$ and $p_{\mathrm{b}}, l_{\mathrm{b}}, q_{\mathrm{b}}, k_{\mathrm{b}}$ are transition rate constants in forward and backward direction. $c_{\mathrm{T}}, c_{\mathrm{D}}$ and $c_{P}$ are the concentrations of ATP, ADP and $P_{i}$, respectively.

with high affinity $[18,40,41]$. The experimental finding that the inhibition constant, $K_{\mathrm{i}}$, of Eqn. 1 is virtually independent of ATP concentration indicates, however, that competition with ATP does not play a significant role in the observed ADP effects.

Within the framework of the Post-Albers scheme, the only remaining possibility for pump inhibition by ADP is the reversal of the phosphorylation step, i.e., the reaction

$\left(\mathrm{Na}_{3}\right) \mathrm{E}_{1}-\mathrm{P}+\mathrm{ADP} \stackrel{p_{\mathrm{b}} \mathrm{c}_{\mathrm{D}}}{\longrightarrow} \mathrm{Na}_{3} \cdot \mathrm{E}_{1} \cdot \mathrm{ATP}$

Increasing the ADP concentration in the medium increases the rate of the backward reaction (3) and thus decreases net pumping rate.

\section{Numerical simulation of the reaction cycle}

The foregoing considerations may be substantiated by a numerical simulation of the Post-Albers reaction cycle [41-43]. The reaction scheme of Fig. 7 is characterized by rate constants $p_{\mathrm{f}}, l_{\mathrm{f}}, q_{\mathrm{f}}$ and $k_{\mathrm{f}}$ for transitions in forward direction and by rate constants $p_{\mathrm{b}} c_{\mathrm{D}}, k_{\mathrm{b}}, q_{\mathrm{b}} c_{\mathrm{P}}$ and $l_{\mathrm{b}}$ for transitions in backward direction. $c_{\mathrm{D}}$ and $c_{\mathrm{P}}$ are the cytoplasmic concentrations of $\mathrm{ADP}$ and $\mathrm{P}_{\mathrm{i}}$, respectively. (In the notation adopted here, the bi- molecular reaction, $\left(\mathrm{Na}_{3}\right) \mathrm{E}_{1}-\mathrm{P}+\mathrm{ADP} \rightarrow \mathrm{Na}_{3} \cdot \mathrm{E}_{1}$ - ATP, is described by a pseudo-monomolecular rate constant, $p_{b} c_{\mathrm{D}}$; the rate constant, $q_{\mathrm{b}} c_{\mathrm{P}}$, is defined in an analogous way.) The numerical analysis is carried out using the following simplifying assumptions:

(a) In both conformations $\left(E_{1}\right.$ and $\left.E_{2}\right)$, the enzyme can bind up to three $\mathrm{Na}^{+}$ions and up to two $\mathrm{K}^{+}$ions. Thus, $\mathrm{E}_{j}(j=1,2)$ can occur in the following forms: $\mathrm{Na}_{3} \mathrm{E}_{j}, \mathrm{Na}_{2} \mathrm{E}_{j}, \mathrm{NaE}_{j}, \mathrm{E}_{j}, \mathrm{KE}_{j}$ and $\mathrm{K}_{2} \mathrm{E}_{j}$. Mixed species such as $\mathrm{NaE}_{j} \mathrm{~K}$ are excluded. The three $\mathrm{Na}^{+}$sits, and also the two $\mathrm{K}^{+}$ sites, are considered to be equivalent.

(b) The rate constants for binding and release of $\mathrm{Na}^{+}$and $\mathrm{K}^{+}$are large, so that the six different forms $\mathrm{Na}_{3} \mathrm{E}_{j}, \mathrm{Na}_{2} \mathrm{E}_{j} \ldots$ are always in equilibrium with each other. If $c_{\mathrm{N}}^{\prime}$ is the $\mathrm{Na}^{+}$concentration at the cytoplasmic side and $x[\mathrm{~A}]$ is the fraction of $\left(\mathrm{Na}^{+}+\mathrm{K}^{+}\right)$-ATPase in form $\mathrm{A}, \mathrm{Na}^{+}$binding at the cytoplasmic side is described by

$\frac{x\left[\mathrm{E}_{1} \cdot \mathrm{ATP}\right]}{x\left[\mathrm{Na} \cdot \mathrm{E}_{1} \cdot \mathrm{ATP}\right]}=\frac{K_{\mathrm{N} 1}^{\prime}}{c_{\mathrm{N}}^{\prime}}$

$K_{\mathrm{N} 1}^{\prime}$ is the equilibrium dissociation constant of $\mathrm{Na}^{+}$for single occupancy at the cytoplasmic side. Analogous equations hold for the other binding equilibria which are described by equilibrium constants $K_{\mathrm{N} 2}^{\prime}, K_{\mathrm{N} 3}^{\prime}, K_{\mathrm{K} 1}^{\prime}$ and $K_{\mathrm{K} 2}^{\prime}$. Assuming that the three sodium sites, and also the two potassium sites, are identical and independent [44], the dissociation constants are given by the following relations:

$K_{\mathrm{N} 1}^{\prime}=\frac{1}{3} K_{\mathrm{N}}^{\prime} ; K_{\mathrm{N} 2}^{\prime}=K_{\mathrm{N}}^{\prime} ; K_{\mathrm{N} 3}^{\prime}=3 K_{\mathrm{N}}^{\prime}$

$K_{\mathrm{K} 1}^{\prime}=\frac{1}{2} K_{\mathrm{K}}^{\prime} ; K_{\mathrm{K} 2}^{\prime}=2 K_{\mathrm{K}}^{\prime}$

$K_{\mathrm{N}}^{\prime}$ and $K_{\mathrm{K}}^{\prime}$ are the intrinsic dissociation constants of the binding sites in state $E_{1}$. The factors $1 / 3,3,1 / 2$ and 2 are the usual statistical coefficients describing binding equilibria in a system of multiple binding sites [45]. Corresponding relations hold for the dissociation constants in state $\mathrm{E}_{2}$.

(c) The rate constants for binding and release of ATP at the binding site in state $\mathrm{E}_{2}$ (low-affinity binding) are large, so that stages $E_{2}\left(K_{2}\right)$ and ATP $\cdot E_{2}\left(K_{2}\right)$ are always in equilibrium with each 
other [41]:

$\frac{x\left[\mathrm{E}_{2}\left(\mathrm{~K}_{2}\right)\right]}{x\left[\mathrm{ATP} \cdot \mathrm{E}_{2}\left(\mathrm{~K}_{2}\right)\right]}=\frac{K_{\mathrm{T} 2}}{c_{\mathrm{T}}}$

(d) Effects of transmembrane voltage on the rate constants are neglected (see Ref. 43 for further discussion of this point).

Numerical values for some of the rate constants of the reaction scheme (Fig. 1) can be estimated using experimental data from the literature. Other parameters have been adjusted by fitting the calculated values of the turnover rate $v_{\mathrm{m}}$ to the observed dependence of $v_{\mathrm{m}}$ on $c_{\mathrm{T}}, c_{\mathrm{D}}$ and $c_{\mathrm{P}}$ (Figs. 3, 5 and 6). In addition to the rate constants, the equilibrium dissociation constants for $\mathrm{Na}^{+}$and $\mathrm{K}^{+}$are required for the calculation of transport rates. Experimental information on binding of $\mathrm{Na}^{+}$and $\mathrm{K}^{+}$to the enzyme is scanty so far $[55,56]$. For the numerical simulation we have chosen a set of binding constants which qualitatively account for the observed dependence of ATP-hydrolysis rate on sodium and potassium concentration [1] and which are consistent with the transport rates observed in this study.

Numerical calculations (see Appendix) of the turnover rate $v$ have been carried out using the values of rate constants and equilibrium constants listed in Table I. Under the conditions of the vesicle experiments $\left(c_{\mathrm{N}}^{\prime}=140 \mathrm{mM}, c_{\mathrm{N}}^{\prime \prime}=10\right.$ $\mathrm{mM}, c_{\mathrm{K}}^{\prime}=10 \mathrm{mM}, c_{\mathrm{K}}^{\prime \prime}=140 \mathrm{mM}$ ) the actual turnover rate $v$ is virtually identical with the maximum turnover rate, $v_{\mathrm{m}}$, in the limit of saturating extracellular $\mathrm{K}^{+}$concentration. (Note that the extracellular $\mathrm{K}^{+}$concentration, $c_{\mathrm{K}}^{\prime \prime}$, corresponds to the intravesicular concentration in the vesicle experiment.)

The results of the numerical simulation are represented in Figs. 3, 5 and 6 (dashed lines). A single set of parameter values (Table I) has been used for the calculation of turnover rates as a function of the concentration of ATP, ADP and $P_{i}$. The values given in Table $I$ refer to a temperature of $25^{\circ} \mathrm{C}$. For an adjustment to the experimental turnover rates which have been measured at $16^{\circ} \mathrm{C}$ and $19^{\circ} \mathrm{C}$ all rate constants have been multiplied by a constant factor $\left(0.36\right.$ at $16^{\circ} \mathrm{C}, 0.58$ at $19^{\circ} \mathrm{C}$ ). It is seen that the calculated turnover rates approximately fit the shape of the experimentally
TABLE I

NUMERICAL VALUES OF KINETIC PARAMETERS (FIG. 7) USED IN CALCULATION OF TURNOVER RATES

All values, if not otherwise indicated, refer to zero voltage and a temperature of $25^{\circ} \mathrm{C}$. Rate constants measured at other temperatures have been approximately corrected using the activation energy of overall ATPase activity $\left(E_{\mathrm{a}} \approx 71 \mathrm{~kJ} / \mathrm{mol}\right.$ ) [51]. $K_{\mathrm{N}}^{\prime}$ and $K_{\mathrm{K}}^{\prime}$, equilibrium dissociation constants of $\mathrm{Na}^{+}$ and $\mathrm{K}^{+}$in state $\mathrm{E}_{1}$ of the enzyme; $K_{\mathrm{N}}^{\prime \prime}$ and $K_{\mathrm{K}}^{\prime \prime}$, dissociation constants in state $\mathrm{E}_{2} ; K_{\mathrm{T} 2}$, equilibrium dissociation constant of ATP from state $\mathrm{E}_{2}\left(\mathrm{~K}_{2}\right) ; K=\bar{c}_{\mathrm{D}} \bar{c}_{\mathrm{P}} / \bar{c}_{\mathrm{T}}$, equilibrium constant of ATP hydrolysis $\left(\bar{c}_{\mathrm{T}}, \bar{c}_{\mathrm{D}}\right.$ and $\bar{c}_{\mathrm{P}}$ are equilibrium concentrations of ATP, ADP and $P_{i}$, respectively).

\begin{tabular}{llll}
\hline Parameter & value & notes \\
\hline$p_{\mathrm{f}}$ & $270 \mathrm{~s}^{-1}$ & $\mathrm{a}$ \\
$p_{\mathrm{b}}$ & $10^{7} \mathrm{M}^{-1} \cdot \mathrm{s}^{-1}$ & $\mathrm{~b}$ \\
$l_{\mathrm{f}}$ & $120 \mathrm{~s}^{-1}$ & $\mathrm{c}$ \\
$l_{\mathrm{b}}$ & $10 \mathrm{~s}^{-1}$ & $\mathrm{~d}$ \\
$q_{\mathrm{f}}$ & $500 \mathrm{~s}^{-1}$ & $\mathrm{e}$ \\
$q_{\mathrm{b}}$ & $1.3 \cdot 10^{7} \mathrm{M}^{-1} \cdot \mathrm{s}^{-1}$ & $\mathrm{e}$ \\
$k_{\mathrm{f}}$ & $80 \mathrm{~s}^{-1}$ & $\mathrm{f}$ \\
$k_{\mathrm{b}}$ & $10 \mathrm{~s}^{-1}$ & $\mathrm{~g}$ \\
$K_{\mathrm{N}}^{\prime}$ & $4 \mathrm{mM}$ & $\mathrm{h}$ \\
$K_{\mathrm{N}}^{\prime \prime}$ & $100 \mathrm{mM}$ & $\mathrm{h}$ \\
$K_{\mathrm{K}}^{\prime}$ & $8 \mathrm{mM}$ & $\mathrm{h}$ \\
$K_{\mathrm{K}}^{\prime \prime}$ & $0.2 \mathrm{mM}$ & $\mathrm{h}$ \\
$K_{\mathrm{T} 2}$ & $30 \mu \mathrm{M}$ & $\mathrm{h}$ \\
$K$ & $2.7 \cdot 10^{5} \mathrm{M}$ & $\mathrm{i}$ \\
\hline
\end{tabular}

a Mårdh and Zetterquist [52] obtained at $21^{\circ} \mathrm{C}$ a value of 180 $\mathrm{s}^{-1}$ for the pseudo-first-order rate constant of phosphorylation of bovine-brain microsomal $\left(\mathrm{Na}^{+}+\mathrm{K}^{+}\right)$-ATPase when neither $\mathrm{Na}^{+}$nor ATP was rate-limiting. See also Mårdh and Lindahl [53].

b This value has been adjusted by fitting the calculated turnover rate to the experimentally observed dependence of $v_{\mathrm{m}}$ on $c_{\mathrm{D}}$ (Fig. 3). A much lower value of $p_{\mathrm{b}}\left(\approx 4000 \mathrm{M}^{-1} \cdot \mathrm{s}^{-1}\right.$ at $21^{\circ} \mathrm{C}$ ) may be estimated from data obtained by Mårdh [54]

c In the presence of $10 \mathrm{mM} \mathrm{K}{ }^{+}$, when the transition $\left(\mathrm{Na}_{3}\right) \mathrm{E}_{1}$ $\mathrm{P} \rightarrow \mathrm{P}-\mathrm{E}_{2} \cdot \mathrm{Na}_{3}$ is thought to be rate-limiting, Mårdh [54] obtained a rate constant of $77 \mathrm{~s}^{-1}$ at $21^{\circ} \mathrm{C}$ for the dephosphorylation of the $\mathrm{K}^{+}$-sensitive form of the phosphoenzyme. With $E_{\mathrm{a}}=71 \mathrm{~kJ} / \mathrm{mol}$ this gives $l_{\mathrm{f}} \approx 120 \mathrm{~s}^{-1}$.

d Ref. 46; enzyme from outer medulla of kidney.

e The value of $q_{\mathrm{f}}$ has been arbitrarily chosen assuming that the reaction $P-E_{2} \cdot K_{2} \rightarrow E_{2}\left(K_{2}\right)$ is not rate limiting [53]. The ratio $q_{\mathrm{b}} / q_{\mathrm{f}}$ has been adjusted by fitting the calculated turnover rate of the observed dependence of $v_{m}$ on $c_{P}$ (Fig. 5).

I Ref. 47; enzyme from outer medulla of kidney.

g Ref. 48 and 49; enzyme from outer medulla of kidney.

h See text.

i Ref. 50; $\mathrm{pH} \mathrm{7.2,1} \mathrm{mM} \mathrm{Mg}^{2+}, 38^{\circ} \mathrm{C}$. 
observed concentration dependence. In particular, the non-competitive inhibition by ADP is reproduced by the simulation. While most parameters have been estimated from literature data (Table I), $p_{\mathrm{b}}, q_{\mathrm{b}}$ and $K_{\mathrm{T} 2}$ have been determined by the fitting procedures. The values of $p_{\mathrm{b}}, q_{\mathrm{b}}$ and $K_{\mathrm{T} 2}$ obtained in this way are not unique but depend on the choice of the other kinetic parameters. Since the data listed in Table I have been partly obtained with enzyme prepared from sources other than kidney medulla, the assignment of numerical values to the kinetic parameters is tentative.

\section{General properties of the rate equation}

It is interesting to discuss the effects of ADP, ATP and $P_{i}$ from a more general point of view. For the reaction cycle represented in Fig. 7 in which binding of ATP and phosphorylation of the protein occur in separate steps, the dependence of turnover rate $v$ on $c_{\mathrm{T}}$ and $c_{\mathrm{D}}$ at zero concentration of $\mathrm{P}_{\mathrm{i}}$ has the general form

$v=v_{\infty} \frac{\alpha c_{\mathbf{T}}}{1+\alpha c_{\mathrm{T}}+\beta c_{\mathrm{D}}+\gamma c_{\mathrm{D}} c_{\mathrm{T}}}$

This rate equation which can be easily derived using the King-Altman formalism [57,58] holds under the condition that ADP acts on the cycle exclusively through reaction (3). $v_{\infty}$ is the turnover rate for $c_{D}=0, c_{T} \rightarrow \infty$, and $\alpha, \beta, \gamma$ are combinations of rate constants, equilibrium constants and the alkali-ion concentrations. Relation (8) has the form of the rate equation for non-competitive inhibition of an enzyme, E [59]:

$v=v_{\infty} \frac{c_{\mathrm{S}} / K_{\mathrm{S}}}{1+c_{\mathrm{S}} / K_{\mathrm{S}}+c_{\mathrm{I}} / K_{\mathrm{I}}+c_{\mathrm{S}} c_{\mathrm{I}} / K_{\mathrm{S}} K_{\mathrm{IS}}}$

$\left(c_{S}, c_{\mathrm{I}}\right.$, concentrations of substrate $\mathrm{S}$ and inhibitor I; $K_{\mathrm{S}}, K_{\mathrm{I}}$, equilibrium dissociation constants of ES and EI; $K_{\text {IS }}$, equilibrium dissociation constant for IES $\rightarrow I+E S$ ). Under the condition $\alpha \beta \approx \gamma$ (corresponding to $K_{\mathrm{I}} \approx K_{\mathrm{IS}}$ ) Eqn. 8 reduces to

$v=\frac{v_{\infty} c_{\mathrm{T}}}{c_{\mathrm{T}}+1 / \alpha}+\frac{1 / \beta}{c_{\mathrm{D}}+1 / \beta}$

This equation has the form of the empirical relation (1). The similarity of Eqns. 8 and 9 means that 'product inhibition' by ADP in the reaction cycle is kinetically indistinguishable from noncompetitive inhibition in which the inhibitor molecule binds to a regulatory binding site which is different from the substrate site.

It should be emphasized that the inhibition by ADP occurs far from the reversal point of the pump. At finite concentration of $\mathrm{P}_{\mathrm{i}}$ the turnover rate is given by $v=\left(A c_{\mathrm{T}}-B c_{\mathrm{D}} c_{\mathrm{P}}\right) / S$ where $A$ is the product of the rate constants for transitions in forward direction and $B$ the product of rate constants for transitions in backward direction; $S$ has the form of the denominator in Eqn. 8. When (at constant $c_{\mathrm{T}}$ and $\left.c_{\mathrm{P}}\right) c_{\mathrm{D}}$ is increased, the thermodynamic driving force, which is proportional to $\left(A c_{\mathrm{T}}-B c_{\mathrm{D}} c_{\mathrm{P}}\right)$, decreases; at large values of $c_{\mathrm{D}}$ pumping would cease. In our experiments, however, in which either $c_{\mathrm{P}}$ or $c_{\mathrm{D}}$ was very small, the driving force was always large. The observed inhibitory effect of ADP does not result from a decrease of the term $\left(A c_{\mathrm{T}}-B c_{\mathrm{P}} c_{\mathrm{D}}\right)$, but rather by an increase of the quantity $p_{\mathrm{b}} c_{\mathrm{D}}$, which is contained in the denominator, $S$.

The effect of $P_{i}$ on the turnover rate at zero ADP concentration is described by a relation analogous to Eqn. 8 in which the denominator is replaced by the expression $c_{\mathrm{T}}+\alpha^{*} C_{\mathrm{P}}+\beta^{*} c_{\mathrm{P}} c_{\mathrm{T}}+$ $\gamma^{*}$. This means that the inhibition by $\mathrm{P}_{\mathrm{i}}$ is expected to be of the non-competitive type, too.

\section{Comparison with previous work}

Studies of ADP effects on pumping rate in reconstituted vesicles in which the nucleotidebinding site is easily accessible from the external medium are described here for the first time. Binding of ADP to solubilized $\left(\mathrm{Na}^{+}+\mathrm{K}^{+}\right)$ATPase or microsomal preparations was previously investigated under various conditions promoting high- or low-affinity binding [17,40,60,61]. The effect of ADP on ATP-hydrolysis rate of microsomal or solubilized $\left(\mathrm{Na}^{+}+\mathrm{K}^{+}\right)$-ATPase from rat brain was found to be competitive with respect to ATP [14,15]. A similar competitive inhibition of ATPase activity by ADP was observed with solubilized and precipitated $\left(\mathrm{Na}^{+}+\mathrm{K}^{+}\right)$ATPase from the outer medulla of porcine kidney [18]. Sodium transport studies with cardiac sarcolemmal vesicles also showed that the $\left(\mathrm{Na}^{+}+\mathrm{K}^{+}\right)$ATPase is inhibited by ADP [62] and the authors claim this effect to be competitive. The reason for 
the discrepancy between the non-competitive action of ADP observed in the present study and the competitive inhibition reported from measurements of enzyme activity is not clear. The observed differences in the kinetic behaviour may reflect differences in the source of the enzyme and/or the method of preparation and experimental conditions. If a competitive interaction of ADP with the low-affinity ATP-binding site occurs under the conditions of our experiments, the effect is likely to be hidden in the much stronger non-competitive inhibition.

Effects of intracellular ADP on alkali-ion transport have been studied in squid axon [7,8,63], skeletal muscle [9] and erythrocyte ghosts [11-13, $64,65]$. In all preparations, ADP was found to increase pump-mediated $\mathrm{Na}^{+} / \mathrm{Na}^{+}$-exchange $[8-13,65]$. On the other hand, in squid axon and skeletal muscle, raising the ADP concentration little affected active ion transport [9,63]. A careful study of the effects of ADP and ATP on ion transport by the $\left(\mathrm{Na}^{+}+\mathrm{K}^{+}\right)$-ATPase in erythrocyte ghosts has been carried out recently by Kennedy et al. [12,13] using ADP- and ATP-regenerating systems. Increasing the ADP concentration from 0.2 to $1.5 \mathrm{mM}$ at $0.5 \mathrm{mM}$ ATP decreased active sodium extrusion at the average by a factor of about 1.5. At higher ATP concentrations $(0.7-0.9 \mathrm{mM})$ the effect of ADP was much smaller; this suggests that pump inhibition by ADP in erythrocytes results mainly from competition with ATP for a common binding-site and only to a negligible extent from the reversal of the phosphorylation reaction. It is feasible that, depending on the kinetic parameters of the reaction cycle, competition with ATP predominates in one type of enzyme in a given ATP concentration range, and in another type of enzyme reversal of the phosphorylation step.

Product inhibition of the $\left(\mathrm{Na}^{+}+\mathrm{K}^{+}\right)$-ATPase by inorganic phosphate has been studied with erythrocytes [66,68], microsomal membranes $[14,19]$ and solubilized enzyme [16]. In agreement with the results of the present study the inhibition occurred only at high $\mathbf{P}_{i}$ concentration $\left(c_{\mathrm{P}}>1\right.$ $\mathrm{mM}$ ) and was non-competitive with respect to ATP.

\section{Appendix}

Calculation of turnover rates

According to the principle of microscopic reversibility, the rate constants and equilibrium constants of the reaction cycle (Fig. 7) are not independent of each other, but are connected by the relation

$\frac{p_{\mathrm{f}} l_{\mathrm{f}} q_{\mathrm{f}} k_{\mathrm{f}}}{p_{\mathrm{b}} l_{\mathrm{b}} q_{\mathrm{b}} k_{\mathrm{b}}} \cdot \frac{K_{\mathrm{N} 1}^{\prime \prime} K_{\mathrm{N} 2}^{\prime \prime} K_{\mathrm{N} 3}^{\prime \prime}}{K_{\mathrm{N} 1}^{\prime} K_{\mathrm{N} 2}^{\prime} K_{\mathrm{N} 3}^{\prime}} \cdot \frac{K_{\mathrm{K} 1}^{\prime} K_{\mathrm{K} 2}^{\prime}}{K_{\mathrm{K} 1}^{\prime \prime} K_{\mathrm{K} 2}^{\prime \prime}} \cdot \frac{1}{K_{\mathrm{T} 2}}=K$

Eqn. A1 holds at zero voltage. $K=\bar{c}_{\mathrm{D}} \bar{c}_{\mathrm{P}} / \bar{c}_{\mathrm{T}}$ is the equilibrium constant of ATP hydrolysis and $\bar{c}_{\mathrm{T}}$, $\bar{c}_{\mathrm{D}}$ and $\bar{c}_{\mathrm{P}}$ are equilibrium concentrations of ATP, ADP and $P_{i}$.

For the numerical evaluation of transport rates in the steady state we introduce the fraction $x\left[\mathrm{~A}_{i}\right]$ of total enzyme present in state $A_{i}$. The quantities $x\left[\mathrm{~A}_{\mathrm{i}}\right]$ can be obtained using the steady-state conditions $\mathrm{d}\left(x\left[\mathrm{~A}_{\mathrm{i}}\right]\right) / \mathrm{d} t=0$. For instance, for species $\left(\mathrm{Na}_{3}\right) \mathrm{E}_{1}-\mathrm{P}$, one has

$$
\begin{gathered}
p_{\mathrm{f}} x\left[\mathrm{Na}_{3} \cdot \mathrm{E}_{1} \cdot \mathrm{ATP}\right]+l_{\mathrm{b}} x\left[\mathrm{P}-\mathrm{E}_{2} \cdot \mathrm{Na}_{3}\right] \\
-\left(l_{\mathrm{f}}+p_{\mathrm{b}} c_{\mathrm{D}}\right) x\left[\left(\mathrm{Na}_{3}\right) \mathrm{E}_{1}-\mathrm{P}\right]=0
\end{gathered}
$$

Additional relations of the form of Eqns. 4 and 7 hold for the species which are in equilibrium with each other. From these equations, together with the condition that the sum of all $x\left[\mathrm{~A}_{\mathrm{i}}\right]$ is unity, the steady-state values of the $x\left[\mathrm{~A}_{\mathrm{i}}\right]$ are determined on a digital computer using the matrix inversion method [67]. The turnover rate, $v$, of the pump is then obtained as the difference of the forward and backward rates at any one of the steps of the reaction cycle, e.g.,

$v=q_{\mathrm{f}} x\left[\mathrm{P}-\mathrm{E}_{2} \cdot \mathrm{K}_{2}\right]-q_{\mathrm{b}} c_{\mathrm{P}} x\left[\mathrm{E}_{2}\left(\mathrm{~K}_{2}\right)\right]$

\section{Acknowledgements}

The authors wish to thank Dr. B. Anner for interesting discussions, M. Roudna for excellent technical assistance and Dr. H. Alpes for the HPLC analysis of nucleotides. This work has been financially supported by Deutsche Forschungsgemeinschaft (Sonderforschungsbereich 156). M.T.N. is an Established Investigator of the American Heart Association. 


\section{References}

1 Skou, J.P. (1975) Q. Rev. Biophys. 7, 401-431

2 Robinson, J.D. and Flashner, M.S. (1979) Biochim. Biophys. Acta 549, 145-176

3 Cantley, L.C. (1981) Curr. Top. Bioenerg. 11, 201-237

4 Schuurmans-Stekhoven, F. and Bonting, S.L. (1981) Physiol. Rev. 61, 1-76

5 Jørgensen, P.L. (1982) Biochim. Biophys. Acta 994, 27-68

6 Glynn, I.M. (1985) in The Enzymes of Biological Membranes, Second Edition (Martonosi, ed.), Vol. 3, pp. 35-114, Plenum Press, New York

7 Brinley, F.J. and Mullins, L.J. (1968) J. Gen. Physiol. 52, $181-210$

8 DeWeer, P. (1970) J. Gen. Physiol. 56, 583-620

9 Kennedy, B.G. and DeWeer, P. (1977) Nature 268, 165-167

10 Nelson, M.T. and Blaustein, M.P. (1980) J. Gen. Physiol. $75,183-206$

11 Glynn, I.M. and Hoffman, J.F. (1971) J. Physiol. (Lond.) $218,239-256$

12 Kennedy, B.G., Lunn, G. and Hoffman, J.F. (1983) Curr. Top. Membrane Transp. 19, 683-986

13 Kennedy, B.G., Lunn, G. and Hoffman, J.F. (1986) J. Gen. Physiol. 87, 47-72

14 Hexum, T., Samson, F.E. and Himes, R.H. (1970) Biochim. Biophys. Acta 212, 322-331

15 Robinson, J.D. (1976) Biochim. Biophys. Acta 429, 1006-1019

16 Robinson, J.D., Flashner, M.S. and Marin, G.K. (1978) Biochim. Biophys. Acta 509, 419-428

17 Ottolenghi, P. and Jensen, J. (1983) Biochim. Biophys. Acta 727, 89-100

18 Sakamoto, J. and Tonomura, Y. (1980) J. Biochem. 87, 1721-1727

19 Post, R.L., Toda, G. and Rogers, F.N. (1975) J. Biol. Chem. $255,10681-10686$

20 Racker, E. and Fischer, L.W. (1975) Biochem. Biophys. Res. Commun. 67, 1144-1150

21 Anner, B.M., Lane, L.K., Schwarz, A. and Pitts, B.J.R (1977) Biochim. Biophys. Acta 467, 340-345

22 Rhoden, V. and Goldin, S.M. (1979) Biochemistry 18, 4173-4176

23 Dixon, J.F. and Hokin, L.E. (1980) J. Biol. Chem. 255 , $10681-10686$

24 Forgac, M. and Chin, G. (1982) J. Biol. Chem. 257, $5652-5655$

25 Karlish, S.J.D. and Stein, W.R. (1982) J. Physiol. (Lond.) $328,333-350$

26 Abeywardena, M.Y., Allen, Th.M. and Charnock, J.S. (1983) Biochim. Biophys. Acta 720, 62-74

27 Brotherus, J.R., Jacobsen, L. and Jørgensen, P.L. (1983) Biochim. Biophys. Acta 731, 290-303

28 Cornelius, F. and Skou, J.C. (1984) Biochim. Biophys. Acta $772,357-373$

29 Skriver, E., Maunsbach, A.B., Anner, B.M. and Jørgensen, P.L. (1980) Cell Biol. Int. Rep. 4, 585-591

30 Skriver, E., Maunsbach, A.B. and Jørgensen, P.L. (1980) J. Cell Biol. 86, 746-754
31 Anner, B.M., Robertson, J.D. and Ting-Beall, H.P. (1984) Biochim. Biophys. Acta 773, 253-261

32 Apell, H.-J., Marcus, M.M., Anner, B.M., Oetliker, H. and Läuger, P. (1985) J. Membrane Biol. 85, 49-63

33 Marcus, M.M., Apell, H.-J., Roudna, M., Schwendener, R.A., Weder, H.-G. and Läuger, P. (1986) Biochim. Biophys. Acta $854,270-278$

34 Hiratsuka, T. (1982) Biochim. Biophys. Acta 719, 509-517

35 Jørgensen, P.L. (1974) Methods Enzymol. 32, 277-290

36 Anner, B.M., Marcus, M.M. and Moosmayer, M. (1984) in Enzymes, Receptors and Carriers of Biomembranes (Azzi, Brodbeck and Zahler, eds.), pp. 81-96, Springer-verlag, Heidelberg

37 Milsmann, M.H.W., Schwendener, R.A. and Weder, H.-G. (1978) Biochim. Biophys. Acta 512, 147-155

38 Albers, R.W., Koval, G.J. and Siegel, G.J. (1968) Mol. Pharmacol. 4, 324-336

39 Post, R.L., Hegyvary, C. and Kume, S. (1972) J. Biol. Chem. 247, 6530-6540

40 Moczydlowski, E.G. and Fortes, P.A.G. (1981) J. Biol. Chem. 256, 2346-2356

41 Moczydlowski, E.G. and Fortes, P.A.G. (1981) J. Biol. Chem. 256, 2357-2366

42 Chapman, J.B., Johnson, E.A. and Kootsey, J.M. (1983) J. Membrane Biol. 74, 139-153

43 Läuger, P. and Apell, H.-J. (1986) Eur. J. Biophys. in press

44 Robinson, J.D. (1983) Curr. Top. Membrane Transp. 19, 485-512

45 Tanford, Ch. (1961) Physical Chemistry of Macromolecules, Ch. 3, John Wiley \& Sons, Inc., New York

46 Glynn, I.M., Hara, Y. and Richards, D.E. (1984) J. Physiol. (Lond.) 351, 531-547

47 Karlish, S.J.D. and Yates, D.W. (1978) Biochim. Biophys. Acta $527,115-130$

48 Karlish, S.J.D. (1980) J. Bioenerg. Biomembranes 12, $111-136$

49 Glynn, I.M. and Richards, E.D. (1982) J. Physiol. (Lond.) $330,17-43$

50 Veetch, R.L., Lawson, J.W.R., Cornell, N.W. and Krebs, H.A. (1979) J. Biol. Chem. 254, 6538-6547

51 Post, R.L., Sen, A.K. and Rosenthal, A.S. (1965) J. Biol. Chem. 240, 1437-1444

52 Mårdh, S. and Zetterquist, Ö. (1974) Biochim. Biophys. Acta 350, 473-483

53 Mårdh, S. and Lindahl, S. (1977) J. Biol. Chem. 252, 8058-8061

54 Mårdh, S. (1975) Biochim. Biophys. Acta 391, 448-463

55 Hastings, D.F. and Skou, J.C. (1980) Biochim. Biophys. Acta $601,380-385$

56 Yamaguchi, M., Sakamoto, J. and Tonomura, Y. (1983) Curr. Top. Membrane Transp. 19, 203-217

57 King, E.L. and Altman, C. (1956) J. Physical Chem. 60, 1375-1377

58 Hill, T.L. (1966) J. Theor. Biol. 10, 442-459

59 Cleland, W.W. (1963) Biochim. Biophys. Acta 67, 173-187

60 Hegyvary, C. and Post, R.L. (1971) J. Biol. Chem. 246, $5234-5240$

61 Yamaguchi, M. and Tonomura, Y. (1978) J. Biochem. 83, 977-987 
62 Philipson, K.D. and Nishimoto, A.Y. (1983) Biochim. Biophys. Acta 733, 133-141

63 DeWeer, P., Kennedy, B.G. and Abercrombie, R.F. (1979) in Na,K-ATPase, Structure and Kinetics (Skou, J.C. and Nørby, J.G., eds.), pp. 503-515, Academic Press, London 64 Beaugé, L.A. and Glynn, I.M. (1980) Nature 280, 510-512 65 Cavieres, J.D. and Glynn, I.M. (1980) J. Physiol. (Lond.) $297,637-645$
66 Garay, R.P. and Garrahan, P.J. (1975) J. Physiol. (Lond.) 249, 51-67

67 Johnson, K.J. (1980) Numerical Methods in Chemistry, pp. 1-503, M. Dekker, New York

68 Eisner, D.A. and Richards, D.E. (1982) J. Physiol. (Lond.) $326,1-10$ 